\title{
Why do people use Artificial Intelligence (AI)-enabled voice assistants?
}

\author{
Suresh Malodia ${ }^{1}$, Nazrul Islam ${ }^{2, *}$, Puneet Kaur ${ }^{3}$, Amandeep Dhir ${ }^{4}$ \\ ${ }^{1}$ Strategic Marketing Area, MICA, Ahmedabad, India \\ 2,* Department of Science, Innovation, Technology and Entrepreneurship, University of Exeter Business School, UK \\ ${ }^{3}$ Department of Psychosocial Science, University of Bergen, Norway \\ ${ }^{4}$ Department of Management, School of Business \& Law, University of Agder, Norway
}

\begin{abstract}
Artificial Intelligence (AI)-enabled voice-assistants such as Alexa and Siri are increasingly replacing the search engines since the consumers are actively using them for accomplishing a variety of their day-to-day tasks. Technology providers as well as marketers increasingly focus on leveraging the use of voice assistants to engage their customers and offer them more personalized value propositions. The study examines the different consumption values associated with the use of voice-assistants. Based on a theoretical framework rooted in the "Theory of Consumption Values" (TCV), we undertake a mixed-method research approach that comprises interviews with experts $(n=5)$ and consumers $(n=30)$ and a cross-sectional survey with active users of voiceassistants $(\mathrm{n}=371)$. Five consumption values were considered namely social identity, convenience, personification, perceived usefulness and perceived playfulness. In addition to this, two types of usage of voice assistants namely information search and task function were considered. Our findings contextualize and extend the TCV framework using voice-assistants technology and get empirical support showing that the consumption values are interrelated. We find that social identity and personification has a strong positive association with both usefulness and playfulness. Furthermore, usefulness and playfulness shared positive association with information search and task function. In addition to this, trust and frequency of use significantly (positive) moderated the association between usefulness and usage of voice assistants. The technology providers and marketers find the research outcome useful to developing various voice-enabled applications and services to enhance the consumer experience and engagement.
\end{abstract}

Keywords: Artificial intelligence, Consumption values, Frequency of use, Theory of consumption value (TCV), Trust, Voice assistant, Virtual assistants 


\section{Introduction}

Artificial Intelligence (AI) has become ubiquitous and integrated into the day-to-day life of consumers, fundamentally transforming customer interactions with stakeholders [1], [2]. Amidst a wide variety of AI-enabled virtual personal assistants, the growth of voice assistants (e.g., Alexa, Siri, OK' Google, etc.) has attracted the attention of marketers and technology providers who are increasingly interested in engaging with their existing and prospective consumers through the medium of voice.

Voice-assistants have recorded the fastest growth in the consumer technology segment next to the growth of smartphones and disrupted the ways humans interact with computers [3]. Accordingly, they have continuously evolved by adapting themselves to serve the user needs most conveniently [4]. Voice-assistant is an AI-enabled virtual-assistant that uses natural language processing algorithms for speech synthesis and recognizes the voice to carry out various complex conversations with users in real-time [5]. Consumers make use of voice-assistants not only to carry out the search function but also to complete tasks such as online shopping, ordering a cab, control their home automation, set reminders, play music, listen to jokes, and so on [6], [7]. Stenvanovic [8] reports that there were nearly 3.25 billion active voice-assistants in 2019 and also predicts that this number will cross the 8 billion mark by 2023.

Given this unprecedented growth, voice-assistants are expected to revolutionize the way consumers interact with the different technology providers. Yet, the theoretical basis of this important practical phenomenon has received less attention. Scholars argue that the use of voice assistants is not limited to the interactions aimed at executing search commands or completing tasks [9]. Instead, consumers tend to express an emotional bonding with their human-like voice-assistants [9]. Although the adoption of voice-assistants is steadily increasing, still many consumers are apprehensive about making use of voice-assistants in their day-to-day life, citing security and privacy risks [10], [11]. Practitioners also suggest that despite the high adoption and rapid surge in the number of voice-based interactions, the actual usage of voice assistants is low, and it is limited to performing basic tasks such as: information search, controlling gadgets, and playing music [10].

Though academic attention is scant, practitioners have emphasized that technology providers and marketers can exploit the inbuilt support provided by voice assistants for handling complex search queries of the consumers for achieving their business objectives [12]. Marketers optimize the voiceassistant Search Engine optimization (SEO) and make the brand, product, or service-related content searchable as per the search algorithm used by voice search engines [12]. Similarly, Klaus and 
Zaichkowsky [13] suggested that since consumers adopting voice-assistant for shopping, both online, as well as offline retailers, are competing to collaborate with various platforms owning these voiceassistants. Academic literature examining the consumer behavior related issues concerning the voiceassistants is currently limited since very few empirical studies do exist on this subject [5]. Kaplan and Haenlein [14] explored and discussed the various applications of voice-assistants, while [6] proposed different content creation strategies for marketing via voice assistants.

To complement this limited body of research, empirical studies examining the consumption values related to the use of voice-assistants are almost non-existent. It is currently not known as to why do consumers make use of voice assistants or in other words, what are the different consumption values sought by the consumers that derive the use of voice-assistants. The current study aims to bridge this gap in the prior literature. The study seeks to answer the following research questions: 1) What are the consumption values associated with voice-assistants and how these consumption values influence the different types of usage (e.g., information search and task function)? 2) How do the different consumption values in the context of voice-assistants are related to each other? 3) Do moderators such as frequency of usage and trust on voice-assistants moderate the strength of the relationship between consumption values and types of usage? Therefore, understanding consumption values pertaining to consumption of voice-assistants is a critical research agenda with implications for practice as well as theory and hence must be addressed.

We draw on the theory of consumption values (TCV) [15] to develop and test the research model. A mixed-method approach was utilized, which consists of a qualitative $(n=35)$ and a quantitative study $(\mathrm{n}=371)$. TCV only offers generic consumption values; thus, we utilized a qualitative study to map the generic consumption values to the voice-assistant specific consumption values as suggested by recent literature [16], [17]. Afterward, the different research questions were answered by evaluating the developed model using a cross-sectional research design consisting of 371 users of voice-assistants.

The present study has first theorized and later empirically validated the extended consumption values in the context of voice-assistant usage. Consequently, this study sheds crucial insights on the different motivations associated with the use of voice-assistants and also significantly contributes to the literature on consumption values. The research findings offer a thorough understanding of how and why consumers are using voice-assistants, what value they derive from using voice-assistants, and what value brings is this technology in its current use. 
This study makes several contributions. First, it empirically extents the generic values by a better understanding of the consumption values that drivers the usage of voice-assistants- new technology that is highly interactive. Second, it contributes to the TCV framework [15] by not only contextualizing and extending it for voice-assistants technology perspectives but also finds empirical support that the consumption values are not at the same level rather interrelated. Third, we find that personification has a strong positive association with both perceived usefulness and perceived playfulness. This further strengthens the typology of relationships that consumers build with their voice-assistants [9]. Fourth, this study observed that the perceived playfulness has a significant association with not only information search but also influence task function which corroborates with the findings of Martin et al. [19] and Venkatesh et al. [20] that the hedonic benefits significantly influence consumer choices while adopting a technology [21]. The manufacturers, technology providers and marketers find the research outcome useful to developing various voice-enabled applications and services to enhance the consumer experience and engagement.

The rest of the study is organized as follows: Section 2 provides a review of the extant literature discussing relevant hypotheses and conceptual framework. Section 3 explains the empirical results and the fourth section presents managerial and theoretical implications. Finally, limitations of the study are discussed along with future research directions.

\section{Literature review}

\subsection{Voice-assistants}

The human desire to hold a conversation with computers has been exemplified through science fiction movies starting from 'space odyssey' released in 1968 to the 2013 movie 'Her' portraying the unique story of a man falling in love with Samantha, a new operating system [5], [22]. In the real world, we recognize Samantha with the names of Alexa and Siri. The software controlling voice-assistant is on a continuous listening mode awaiting for a keyword to wake up [4]. Upon hearing the keyword, it starts recording the user's voice and transmits it to the main server, which processes the voice message using natural language processing and machine learning algorithms. The server responds to the user's command and transmits the reply to the voice-assistant, which is then played back for the user [5]. This communication process facilitates consumers to strike a natural conversation with their voice assistants [9]. The dominant voice-assistants currently available in the market and their key functions are described in Table 1. 
Table 1. The dominant voice assistants and their key functions

\begin{tabular}{|c|c|c|c|c|c|c|c|c|c|c|c|c|c|c|}
\hline & & & \multicolumn{12}{|c|}{ Functions performed by Voice-Assistant } \\
\hline Voice Assist & Owned b. & No of users & 1 & 2 & 3 & 4 & 5 & 6 & 7 & 8 & 9 & 10 & 11 & 12 \\
\hline Alexa & Amazon & >100 Millio & $\sqrt{ }$ & $\sqrt{ }$ & $\sqrt{ }$ & $\sqrt{ }$ & $\sqrt{ }$ & $\sqrt{ }$ & $\sqrt{ }$ & $\sqrt{ }$ & $\sqrt{ }$ & $\sqrt{ }$ & $\sqrt{ }$ & $\sqrt{ }$ \\
\hline Siri & Apple & 375 million & $\sqrt{ }$ & $\sqrt{ }$ & & & $\sqrt{ }$ & $\sqrt{ }$ & $\sqrt{ }$ & $\sqrt{ }$ & $\sqrt{ }$ & $\sqrt{ }$ & $\sqrt{ }$ & $\sqrt{ }$ \\
\hline OK' Google & Google & 500 Million & $\sqrt{ }$ & $\sqrt{ }$ & $\sqrt{1}$ & $\sqrt{ }$ & $\sqrt{ }$ & $\sqrt{ }$ & $\sqrt{ }$ & $\sqrt{ }$ & $\sqrt{ }$ & $\sqrt{ }$ & $\sqrt{ }$ & \\
\hline Cortona & Microsoft & 800 million & $\sqrt{ }$ & $\sqrt{ }$ & & & $\sqrt{ }$ & $\sqrt{ }$ & & & $\sqrt{ }$ & & & \\
\hline Bixby & Samsung & $>10$ Million & $\sqrt{ }$ & $\sqrt{ }$ & $\sqrt{ }$ & $\sqrt{ }$ & $\sqrt{ }$ & & & & $\sqrt{ }$ & & & \\
\hline HelloJio & Jio* & NA & $\sqrt{ }$ & $\sqrt{ }$ & & $\sqrt{ }$ & $\sqrt{ }$ & $\sqrt{ }$ & & & $\sqrt{ }$ & & & \\
\hline Nina & Nuance** & NA & $\sqrt{ }$ & & $\sqrt{ }$ & & & $\sqrt{ }$ & $\sqrt{ }$ & & & & $\sqrt{ }$ & \\
\hline AliGenie, & Alibaba & 500 Million & $\sqrt{ }$ & $\sqrt{ }$ & $\sqrt{ }$ & & $\sqrt{ }$ & $\sqrt{ }$ & & $\sqrt{ }$ & $\sqrt{ }$ & & $\sqrt{ }$ & \\
\hline
\end{tabular}

1 - search, 2 - texting \& email, 3 - shopping, 4 - customer support, 5 - updates (news, weather, etc.), 6 - play music, 7 - traffic navigation, 8 - control other devices, 9 - set reminders \& alarms, 10 - play games, 11 - make payments, 12 - tell a story or a joke.

*This is available on my Jio app which has over 100 Million downloads

**50 Thousand Downloads (data is not available on the internet on the active number of users)

Voice-assistants are increasingly replacing conventional search engines because the voice assistants handle complex search queries of the consumers [6]. For example, consumers can ask the voice assistant to search for "the best smartwatch brand under \$50 (USD)" or "which is the best organic honey in the market". Similarly, there are also a growing number of studies suggesting that consumers are using voice-assistants for placing online orders for their shopping needs [13].

There is a paradigm shift in using voice-assistants to shop online [13]. Three main phenomenological observations are: (a) consumers are increasingly using product attributes or product benefits as a search criterion, e.g., they use search terms such as 'organic honey' and 'hand-crafted silk scarf' [23]; (b) consumer interaction is shifting from searching directly for the brands to asking questions about the brand to their voice-assistants. This information is retrieved by algorithms of the respective voice-assistants, which ultimately influence the consumer purchase decision making; and (c) consumer choices are shifting from visual stimuli to audio stimuli of their voice assistants. 
There are some attempts in the literature to explore the psychological dimension related to consumer's decision making in the context of AI and how AI-based disruptive technologies such as voice assistants are influencing consumer choices [5], [6]. However, it remains unknown at present as to what are the consumption values sought from the use of voice-assistants to complete actions ranging from information search, performing different tasks. A better understanding of consumption values specific to voice-assistants will be useful for marketers to develop and redesign consumer interactions using voice-assistants and offer a superior value proposition to their existing and prospective consumers. The current study aims to address this gap, and it utilizes the TCV framework as an overarching theoretical framework in the context of voice-assistants.

\subsection{Technology adoption literature}

The adoption and use of new technology across various domains have invariably been explained by using the technology acceptance model (TAM) model. Though TAM offers an overly simplified explanation of drivers of behavioral intentions to adopt a new technology it is criticized for its inability to explain the actual usage. The behavioral intentions often do not converge into the actual behavior and hence, TAM is criticized as it fails to predict the actual use behavior [24]. The unified theory of acceptance and use of technology (UTAUT) is an improvised version of TAM aimed at addressing the limitations of the initial model and claims to explain the ongoing use of technology. The UTAUT though is grounded in TAM, theory of reasoned action (TRA), theory of planned behavior (TPB), social cognitive theory and diffusion of innovations model it has been criticized for numerous shortcomings. Bagozzi [25] criticized UTAUT for being too complex and chaotic. Similarly, Van Raaij and Schepers [26] further evaluated the model and concluded that the model was less parsimonious as compared to TAM and the explained variance was significant only when the four moderators are included in the model.

Given that, consumers perceive voice-assistants beyond a technological device and their interaction with the device is conversational, the existing theoretical models offer little insights on this dimension. Additionally, in the context of voice-assistants, the adoption of technology is a given, as consumers readily interact with technology [27]. Voice-assistant is rather a companion of consumers and hence, for brands to be able to design effective voice applications it is important to understand how consumers choose to interact with their voice-assistants on a routine basis and what determines the usage. Thus, 
TCV can be a useful theoretical framework that is based on actual usage of the technology to advance our understanding of this new domain

\subsection{Theory of consumption values}

The theory of consumption values (TCV) can be used as a theoretical paradigm to understand the consumption and use of new technologies and innovations by the consumers [17]. According to TCV, consumer's decision to adopt and use technology is a voluntary choice that they make based on the 'perceived consumption value' associated with the use of the selected product, brand, or service [15], [16], [17]. TCV combines both intrinsic and extrinsic behavioral dimensions that drive the consumption decision, i.e., to use or not to use, how much to use and when to use a product or a service [28], [29]. Sheth et al., [15] argue TCV is axiomatic since it can be applied in multiple contexts, and it has been validated across 200 product categories. In the context of voice-assistants, the TCV framework is relevant since it is not limited to purchase decisions only. Still, it can provide insights about the decision of consumers on whether to engage or not with their voice-assistants regularly. Furthermore, TCV can be useful in the context of technology products such as voice assistants as it has been validated in the context of micro-computers and video recording devices [15], IT/digital artifacts [30] such as social media and navigation devices [28]. However, in comparison to the extended body of prior TCV literature, to the best of our understanding, no prior study has examined the consumption values in the context of voice assistants.

\section{Extending TCV consumption values from the voice-assistants perspective}

The recent literature on TCV is in favor of using context-specific measures compared to generic measures to understand how consumption values vary in the context of products and services [16], [17]. Scholars have emphasized that TCV offers a framework for contextualizing the generic values in specific contexts for a better understanding of how consumers value products and services [16], [17]. Therefore, we contextualize the generic consumption values by understanding the specific values that consumers derive from the use of voice-assistants (Table 2). TCV offers three major propositions. These are as follows: a) adoption of a new product or technology is a function of five consumption values [15], b) each consumption value has a differential contribution [15], and c) the consumption values are not independent of each other instead they share some kind of associations as suggested by the recent literature [17]. 


\subsection{Qualitative study}

We used qualitative research to identify context specific consumption values. Qualitative research included in-depth interviews (5 experts, and 30 consumers), and content analysis of the popular online information sources. First, we interviewed five experts, out of which, three experts were working in the industry at senior positions handling strategic business units related to voice-assistants and the other two experts were senior researchers. The latter has published extensively in the area of digital technology and digital marketing. The experts were asked the following questions: (1) What are the primary and secondary needs of consumers based on the existing use cases of voice-assistants. (2) How the adoption of voice-assistants was evolving. (3) How consumers were buying voice-assistants. (4) What opportunities voice-assistants can provide to the technology providers and brands. (5) What the concerns are in the adoption of voice-assistants. The industry experts helped us in identifying the factors related to the use of voice assistants from the perception of the industry. It also helped us design an interview schedule for the consumers.

In the next step, we interviewed thirty existing consumers of different voice-assistants. The interviewees had extensive experience of using voice-assistants for at least six months (17 males and 13 females; aged between 19 years - 53 years). To obtain an in-depth understanding of the usage of voice-assistants, an aided recall strategy was adopted during the interviews. The participants were given multiple usage scenarios (book a cab, controlling IoT devices, news updates, order online, playing music, search internet etc.,) as stimuli to help them recall their past usage and share the experience of using voice-assistants. We asked questions related to various occasions, duration, frequency, and types of use, and the perceived benefits they associate with using voice-assistants. The qualitative data were analyzed using an affinity mapping technique, and recurring themes were identified as suggested by other scholars [16]. Affinity mapping is a data analysis technique used to analyze qualitative data [18]. Researchers employed a team of four research associates to carry out affinity mapping by spreading research notes on post it slips on a soft board. Next the notes were arranged into groups to identify themes. Following themes were identified in this process: a) ease of use, b) convenient, c) faster, d) personalized, e) saves time, f) part of a lifestyle, g) fun and enjoyment, h) practical utility, and i) beneficial.

After the interviews, qualitative content analysis on popular online news articles, marketing blogs, and consumer reviews about Amazon Alexa and Amazon Echo published between 2018 and 2020 about different voice-assistants to understand the major sentiments related to different values 
consumer perceive from the voice-assistants. This approach is popularly utilized in the prior marketing literature [57]. The qualitative content analysis of 12 articles and 80 consumer reviews further strengthened the themes identified through the interviews with 30 consumers of voice-assistants. A panel of academic experts (two professors and two research associates) with expertise in qualitative research techniques and one industry expert having expertise in voice-assistants reviewed the first pool of research themes. The panel suggested to combine similar themes and also suggested to drop redundant themes further; we organized the remaining themes into relevant consumption value. The raters achieved sufficient inter-coder reliability as measured using Cohen's Kappa [71].

The final pool of themes was mapped with prior TCV literature to develop and map the different context-specific consumption values associated with the use of voice assistant to the generic TCV proposed by other scholars. The final set of consumption values were 'perceived usefulness' (generic value - functional value), 'social identity' (generic value - social value), 'personification' (generic value - emotional value), 'perceived playfulness' (generic value - epistemic value, and 'convenience' (generic value - conditional value) (Table 2). The qualitative data has suggested that trust and frequency of use as the two influential variables that influence the consumption values and the usage of voice assistants. Due to this reason, the current study has examined their moderating role in the studied associations.

Table 2. Mapping of generic values and extended values of TCV

\begin{tabular}{|c|c|c|c|}
\hline Generic Value & Proposition & Extended Value & Proposition \\
\hline Functional Value & $\begin{array}{l}\text { The value is derived from the } \\
\text { utilitarian attributes of a product } \\
\text { (functional or physical). [15] }\end{array}$ & $\begin{array}{l}\text { Perceived } \\
\text { usefulness }\end{array}$ & $\begin{array}{l}\text { The extent to which consumers } \\
\text { perceive voice-assistants to be } \\
\text { useful enhances the value } \\
\text { consumers derive by using their } \\
\text { voice-assistants. }\end{array}$ \\
\hline Emotional Value & $\begin{array}{l}\text { The value is derived from the } \\
\text { ability of a product to arouse } \\
\text { feelings. [15] }\end{array}$ & Personification & $\begin{array}{l}\text { The extent to which } \\
\text { personifying voice-assistants } \\
\text { arouse emotions among } \\
\text { consumers of voice-assistants. }\end{array}$ \\
\hline Social Value & $\begin{array}{l}\text { The value is derived from the } \\
\text { association of a product with socia } \\
\text { imagery and the ability of the } \\
\text { product to boost self-image. }[15]\end{array}$ & Social identity & $\begin{array}{l}\text { The extent to which using } \\
\text { voice-assistants helps } \\
\text { consumers to affirm their social } \\
\text { identity. }\end{array}$ \\
\hline Epistemic Value & $\begin{array}{l}\text { The value is derived from the } \\
\text { ability of a product to entice } \\
\text { inquisitiveness, offer uniqueness, } \\
\text { or satisfy the pursuit of knowledge } \\
\text { [15] }\end{array}$ & $\begin{array}{l}\text { Perceived } \\
\text { playfulness }\end{array}$ & $\begin{array}{l}\text { The extent to which consumers } \\
\text { perceive using voice-assistants } \\
\text { to be playful and enjoyable. }\end{array}$ \\
\hline
\end{tabular}




\begin{tabular}{|l|l|l|l|}
\hline Conditional Value & $\begin{array}{l}\text { The value derived from a product } \\
\text { in the context of a set of } \\
\text { circumstances. [15] }\end{array}$ & Convenience & $\begin{array}{l}\text { The extent to which using voice- } \\
\text { assistant creates convenience for } \\
\text { users under specific conditions. }\end{array}$ \\
\hline
\end{tabular}

\section{Research framework and hypotheses development}

The research framework (Figure 1) consists of the five consumption values as the latent constructs and two dependent variables, namely, information-seeking behavior and task behavior. The consumption values are assumed to be hierarchical, wherein social value, conditional value, and emotional value leads to functional and epistemic value. The research model also examines the moderating role of frequency of use and trust on voice-assistants while controlling for age and education.

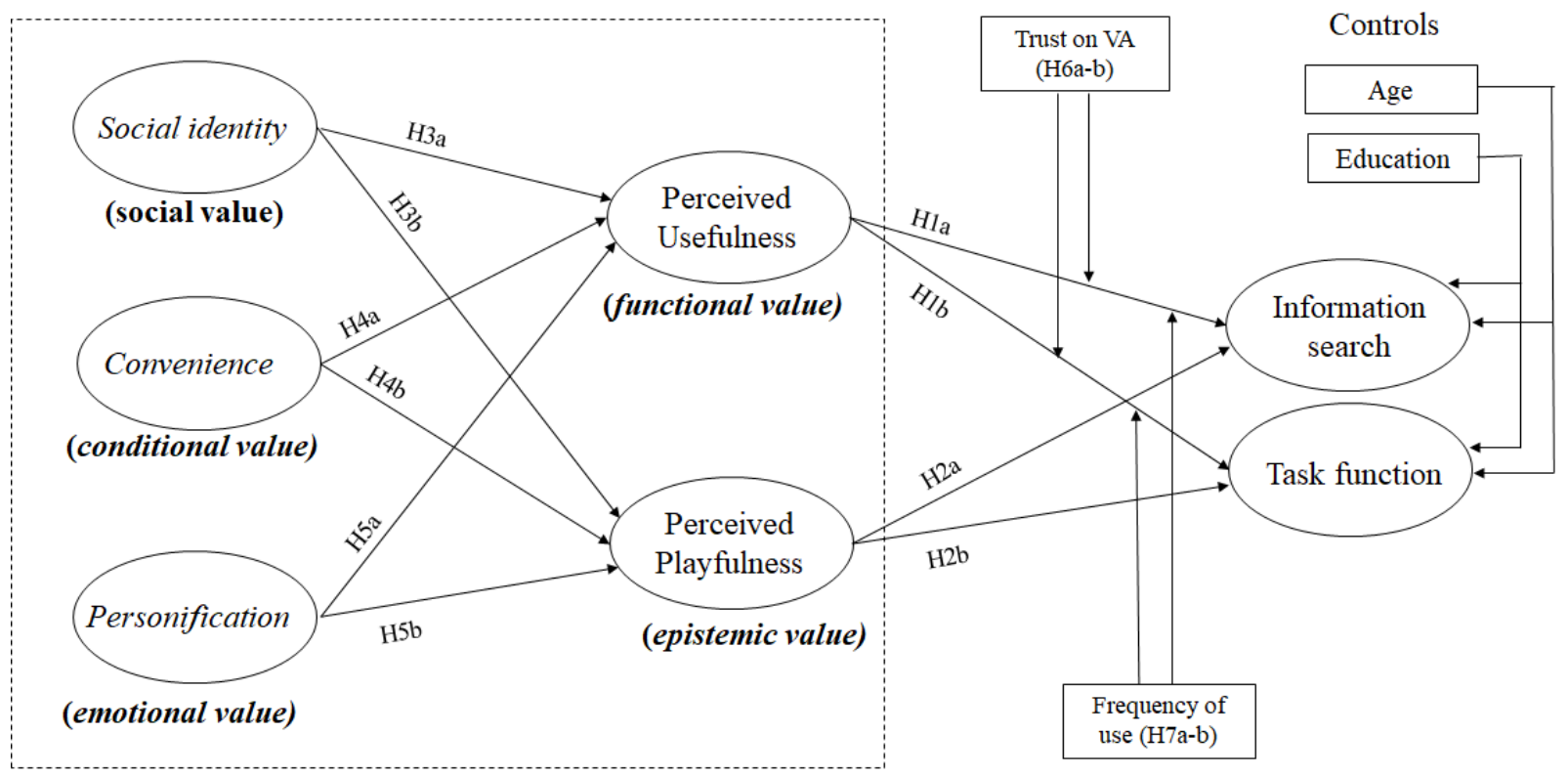

CONSUMPTION VALUES

Figure 1. Research Framework

\subsection{Perceived usefulness (functional value)}

The prior research discussed the significance of functional value in predicting the behavioral intentions and use behavior of new-age technology products and services [16], [31], [32]. Functional value is conjoint of perceived utility consumer derives from different attributes of a product or service and is characterized as perceived utilitarian value or simply perceived usefulness [15], [33]. Functionality has been identified as an important benefit that consumers seek from using a smart speaker [34], [35]. The 
scholarly research examining the adoption of AI-based products shows that perceived usefulness significantly influences the adoption and usage of AI-enabled devices such as virtual personal assistants [1], [36], [37]. Moriuchi [1] found that perceived usefulness positively influences the users' engagement with google assistant for transactional as well as non-transactional activities. Consumers use voice-assistants for multiple purposes such as information search, asking questions, and completing tasks such as controlling their IoT devices, book taxi via Uber, place orders online and make payments, etc. Hence, we advance the following hypotheses:

H1a: Perceived usefulness is positively associated with information search in the context of voiceassistants.

H1b: Perceived usefulness is positively associated with task function in the context of voice-assistants

\subsection{Perceived playfulness (epistemic value)}

Extant research has suggested that epistemic value, i.e., consumers desire to explore new technologies and learn new practices significantly influences the use of new technology such as mobile apps, virtual products in online games, hyped technology artefacts, etc. [16], [32], [38]. Consumers derive epistemic value by using products having the ability to arouse curiosity or offer a pleasurable experience because of unique attributes [15]. Park and Lee [39] identified perceived playfulness as a feeling of an individual's curiosity and observed its strong association with purchase intentions. The existing literature characterizes playfulness as the tendency of consumers to interact with the new technology instinctively and innovatively [40]. Yang et al., [41] identified playfulness as an important component of value in the context of wearable devices and Kowalczuk, [36] found that perceived enjoyment in the context of smart speakers was significantly associated with behavioral intentions. The attribute of playfulness has utilitarian benefits and acts as a motivational force influencing the use of behavior [42]. If a consumer feels good about interacting with their voice-assistants, they would be intrinsically motivated to use it more frequently and are likely to experience a high degree of engagement. Since voice-assistants are capable of carrying out an asynchronous conversation, consumers playfully use their voice assistants to carry out both searches as well as complete various tasks. Therefore, we advance the following hypotheses:

H2a: Perceived playfulness is positively associated with information search in the context of voiceassistants.

H2b: Perceived playfulness is positively associated with task function in the context of voice-assistants 


\subsection{Social identity (social value)}

The social identity is a psychological state used by individuals to collectively represent who they are and where they belong by associating themselves with certain social groups [43]. It is argued that consumers derive value from their social identity and the perceived membership of social groups is of emotional significance for them [44]. Social identity motives such as self-expression, enhancing selfimage, and self-esteem has been advocated as key contributors for developing strong associations between consumers and the technology providers [43].

The literature suggests that a substantial amount of social identity motives are embedded in innovative products and services such as smartphones, AI-enabled products, mobile apps, and digital artefacts, [30], [45]. According to Truel et al. [30], using digital artefacts helps consumers to identify themselves as sophisticated or trendy and hence provide significant social value. Bødker et al. [45] argue that consumer uses the newest smartphone, such as the iPhone that is highly noticeable to identify themselves with a certain social stratum. Similarly, Ogbanufe and Gerhart [46] argue that consumers purchase a smartwatch to affirm their social identity and hence enhances purchase intentions [47]. Furthermore, Talwar et al. [16] found that consumers use mobile apps, as it not only stimulates social approval but also helps users build a strong positive image. Hence, we argue that social identity is a strong driver of social value.

Social identity affects how consumers perceive and evaluate various offerings both cognitively as well as emotionally which further results in shaping consumer behavior by influencing their attitudes and beliefs [48], [49]. It is argued that the value perception in the minds of consumers gets intensified if a product or a service can reinforce their self-identity and hence, consumers perceive such products to be more useful [50]. Similarly, amidst the rapid evolution of social media and virtual digital environment, consumers not only seek identity expressiveness but also look to experience fun and enjoyment [51]. For example, consumers are playful by selecting various avatars for expressing their social identity while playing online games to experience fun and entertainment [52]. Therefore, social identity has a positive effect on perceived usefulness as well as perceived playfulness. Based on the above arguments, we propose the following hypotheses:

H3a: Social identity is positively associated with usefulness

H3b: Social identity is positively associated with playfulness 


\subsection{Convenience (conditional value)}

The conditional value refers to the perceived utility, which is acquired in a specific context, location, or time [16]. For example, consumers use go-pro to capture adventurous moments such as bungee jumping or scuba diving. Similarly, some products are relevant only during festive seasons, while some products are subtly associated with specific conditions such as drinking beer while enjoying a football game [28]. Studies related to consumption values in the context of digital gadgets refer to 'convenience' as an important conditional value that consumers seek while using the product [45]. [32] also adopt convenience as a measure of conditional value and postulates that ability to push location-based data over a smartphone is an important condition to make location-based services more useful. In the context of voice-assistants, the location of the user may influence the decision to use the voice-assistant. For example, a user may wish to turn on his air conditioner remotely or arm the door of his house-sitting at the terrace. Similarly, a user may perceive a voice-assistant to be useful while he is engaged in a certain activity such as using a voice-assistant while driving to connect calls or search information [53]. Voice-assistants perform functions that allow consumers to not only save time but also complete the task with convenience in specific conditions. The convenience in the context of specific activities, situations, or location, influences the usage of voice-assistants and hence can be used to represent conditional value in the context of voice-assistants.

Chang et al., [54] argue that time, place, and execution convenience significantly reduces the cognitive and affective efforts enhancing the efficiency of consumers and making them feel the flow [55]. With the increased efficiency consumers tend to experiment more which results in enjoyment and playfulness [56]. The convenience in the context of voice-assistants not only allows users to complete a wide range of tasks anytime, hands-free, and with simple voice commands allowing them to multitask it also offer flexibility and allow consumers to be experimental and playful. Hence, we propose the following hypotheses:

H4a: Convenience is likely to have a positive effect on the usefulness

H4b: Convenience is likely to have a positive effect on playfulness

\subsection{Personification (emotional value)}

Emotional value refers to the capabilities of the product and service to evoke feelings and emotions [15]. Consumers are often emotionally attached to their possessions and draw emotional value by personifying such products [57]. Literature confirms that IT gadgets arouse emotions and consumers 
feel emotionally attached to their personified digital assets as their virtual partners or pseudo girlfriend [57]. Unlike other technological devices, voice-assistant is a conversational agent, and hence, users personify it with human-like traits [58]. Boonrod and Ketavan [22] reported that consumers share an emotional bonding with their voice-assistants as it helps them fulfill their hedonic desire to feel like they are communicating with a human being while interacting with their voice-assistant. The current study measures personification (a form of emotional value), which refers to the attribution of humanlike qualities and characteristics to imagined non-human agents and voice assistants [59].

Scholars have suggested a positive association between personification, usefulness, and playfulness. To begin with, Pradhan et al. [60] found that older users of voice assistants showcase a positive association between their personification of voice-assistants and their interactions. Schweitzer et al. [9] explored the typology of relationships consumers build with their personified voice-enabled devices. The study argues that consumers personify their voice-assistants either as a friend, partner, servant, or as a master. When personified as a friend or a partner, the consumers associate their voiceassistants with fun, playfulness, and accomplish social interaction tasks [9]. Whereas, when a voiceassistant is personified as a servant, consumers perceive it useful and interact with their voice-assistants to derive utilitarian values [9]. Therefore, based on the aforementioned discussion, it is likely that personification is likely to be positively associated with playfulness and usefulness of the voiceassistant. Therefore, we advance the following hypotheses:

H5a: Personification is positively associated with usefulness.

H5b: Personification is positively associated with playfulness.

\subsection{Moderators}

Identifying and validating moderators enhances our understanding of boundary conditions and individual differences observed in consumer behavior [61]. A review of the prior literature reveals that trust remains a primary concern among users of AI-based smart devices [62]. Wells et al. [63] found that consumers' trust in smart speakers is relatively low as compared to other technological devices such as computers and smartphones. The literature identifies trust as an enabler of user engagement [74]. Similarly, it is observed that lack of trust results in the user's aversion [65]. While it is evident that the adoption and usage of voice-assistants are increasing at an unprecedented rate, consumers are also skeptical about trusting voice-assistants [66]. Consumers perceive voice-assistants as intrusive, and it is reported that approximately one-third of users are not comfortable sharing their financial and personal details over voice-assistants due to security concerns [10]. We also found in our qualitative 
study that while searching for information about products and brands through voice-assistants, consumers are apprehensive that this may lead to unnecessary marketing calls. The consumers who trusted their voice-assistant perceived that their search information would not be used for commercial purposes, and it was found that such consumers extensively used their voice-assistants to search for information. Based on the above literature and our qualitative interviews, we propose that trust in voiceassistants will influence the usage of voice-assistants. Therefore, we test the following hypotheses

H6a-b: Trust will positively moderate the association between usefulness and usage of voiceassistants, playfulness, and usage of voice-assistants.

Using a new technology frequently enhances the familiarity and comfort level of the consumer and hence the frequency of using new technology has been argued to moderate the usage of new products or services [67]. Marketers differentiate between heavy users from light users in their market segmentation strategy, which indicates that the frequency of use significantly positively moderates the use of behavior [68]. Similarly, Baptista and Oliveira [69], found that the frequency of use positively moderates the usage of mobile banking services. In the context of voice-assistants, frequent users are likely to become more proficient in using various features of voice-assistants and hence may develop a habit of using voice-assistants intuitively. Therefore, we advance the following hypotheses.

H7a-b: Frequency of use positively moderates the relationship between usefulness and usage of voiceassistants, i.e., information search and task functions.

\subsection{Controls}

The prior literature has noted confounding effect of demographic variables on the related consumer behavior [4], [16]. McLean and Osei-Frimpong [4] suggested that age, gender, educational background, and household size controls usage of in-home voice assistant. Similarly, in the context of new technology adoption, it has been further argued that since younger people are more likely to adopt new technologies [20]. Based on the evidence from prior literature and insights from qualitative study, we argue that demographic variables i.e., age, and education may have a confounding effect on use of voice-assistants. 


\section{Research Method}

To identify and measure the context-specific consumption values regarding the voice assistants, we have utilized a mixed-method research design [16], [70]. The research design consists of qualitative interviews [16] which includes in-depth interviews with experts $(n=5)$, end-users $(n=30)$, and a qualitative content analysis of popular online news articles and consumer reviews related to Alexa and Amazon Echo (Figure 2). Qualitative study helped us contextualize the consumption values and formulate research hypotheses. Next, we conduct quantitative research using an online cross-sectional survey with 371 active consumers of voice-assistants to validate the hypotheses proposed in research framework.

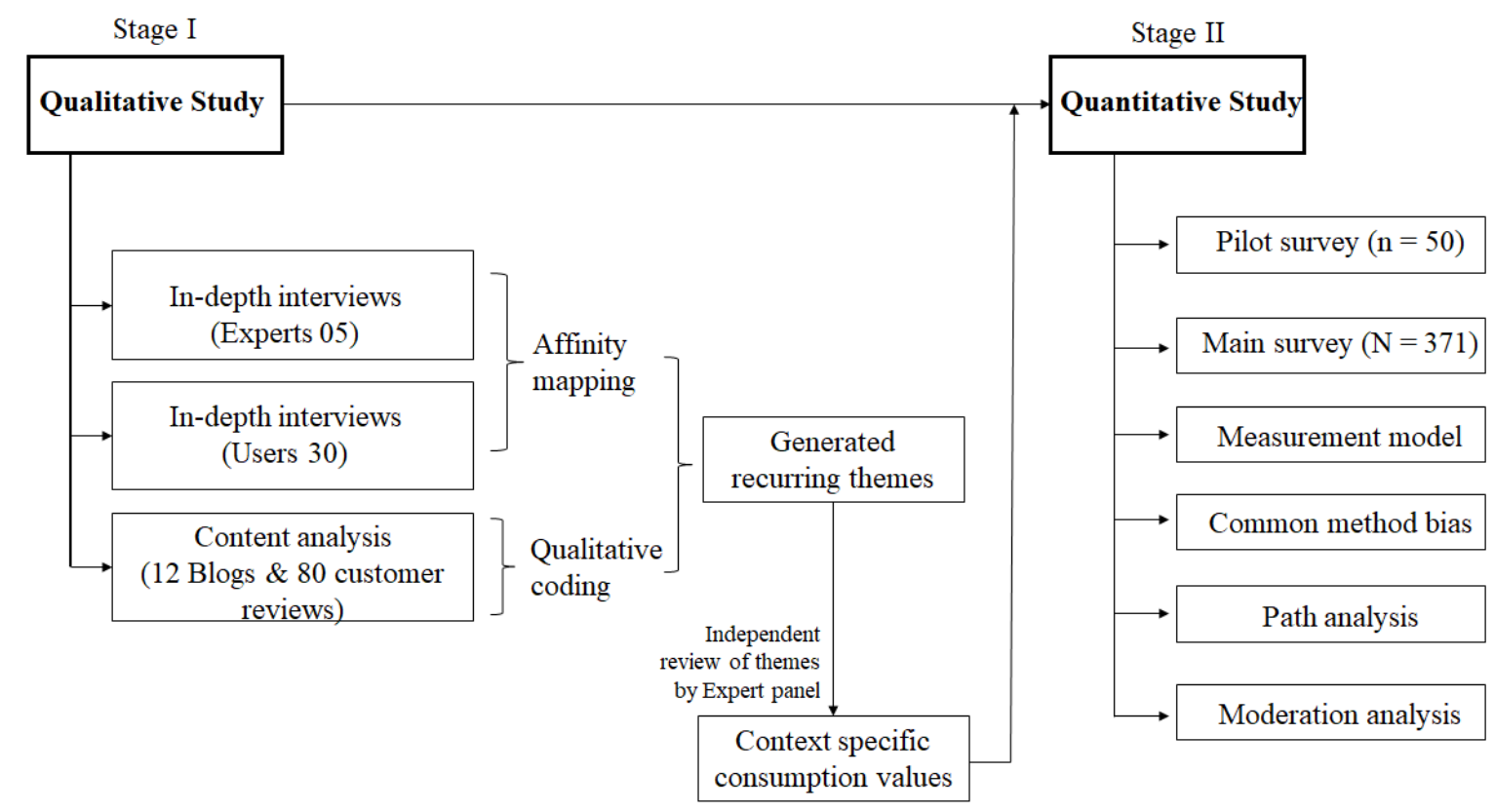

Figure 2. Overview of the research outline

\subsection{Quantitative study}

Finally, a pre-test of the above consumption values was conducted using a pilot survey to establish the quality of the survey instruments on parameters such as readability, clarity, and unambiguity. Further, we used a cross-sectional survey to collect responses from 371 active users of voice-assistants to empirically validate the five consumption values and their impact on the usage of voice-assistants. We discuss the quantitative study by first presenting the proposed hypotheses, and subsequently, we present our analysis. 


\subsection{Sample and data collection}

A random sample was selected from an online survey panel, and data were collected from 371 respondents. The online panel was used for two reasons. First, it provided us with a sampling frame at a global level, and second, it helped us select a random sample. Screening questions were asked to select respondents with experience of using voice-assistants for at least three months. Data cleaning was done to remove incomplete responses, non-engaged respondents, and outliers. A usable sample of 371 respondents was obtained after cleaning the data (Table 3). Further, we carried out pre-processing of data to test the following: (a) normality test, (b) test of multi-collinearity, and (c) homoscedasticity. The three conditions for multi-variate analysis were satisfied and hence, we decided to proceed for the analyzing data using structural equation modelling.

It was observed that the data collected were comparable across geographic locations, gender, and age groups. The respondents were using one of the following voice-assistants: Amazon Alexa, Apple Siri, and Ok Google. These voice-assistants were chosen for the study as they had the capability of carrying out multiple functions. One-third of respondents (36.4\%) reported using their voice-assistants for multiple purposes, i.e., for carrying out transactions, conducting information search, and completing various tasks. Moreover, these voice-assistants can be integrated with unique brands; they can order a cab, book a flight ticket, replenish groceries, etc. [4].

Table 3. Sample characteristics

\begin{tabular}{|c|c|c|c|}
\hline & & Total & Percentage \\
\hline \multirow{2}{*}{ Gender } & Male & 207 & $55.79 \%$ \\
\hline & Female & 164 & $44.20 \%$ \\
\hline \multirow{5}{*}{$\begin{array}{c}\text { Age } \\
\text { (in years) }\end{array}$} & $18-24$ & 87 & $23.45 \%$ \\
\hline & $25-34$ & 94 & $25.34 \%$ \\
\hline & $35-44$ & 76 & $20.48 \%$ \\
\hline & $45-54$ & 64 & $17.25 \%$ \\
\hline & $<=55$ & 50 & $13.48 \%$ \\
\hline \multicolumn{2}{|c|}{ Total } & 371 & $100 \%$ \\
\hline
\end{tabular}




\subsection{Data analysis}

A two-step approach was adopted to analyze the data where we first build a confirmatory model followed by the structural model [72]. The confirmatory model was used to test the reliability and validity of constructs in the research framework, whereas the structural model helped us examine the strength and significance of the structural paths proposed in the research framework.

\section{Results}

\subsection{Measurement model}

Confirmatory factor analysis (CFA) was carried out using AMOSS 21.0 to establish validity measures of the measurement model along with assessing the goodness of fit and construct reliability. CFA was used to examine the psychometric properties of all seven constructs. In addition to the measurement model results, the reliability of the construct, its uni-dimensionality, and validity was assessed using the average variance extracted (AVE), and composite reliability (Table 4). Further, all item loading was greater than 0.60 (higher than the recommended cut-off value 0.40 suggested by Hair et al., [73] and hence establishing item reliability. Finally, assessment of multi-collinearity confirmed that multicollinearity issue was absent in our model. The summary of model fit indices for both measurement and structural model are presented in table 5. 
Table 4. Confirmatory factor analysis

\begin{tabular}{|c|c|c|}
\hline Study Measure* & Measurement items & $\begin{array}{r}\text { Factor } \\
\text { Loadings }\end{array}$ \\
\hline \multirow[t]{7}{*}{ Personification (PR) [74] } & The voice assistant sounds like a human to me. & 0.81 \\
\hline & I find my voice assistant friendly & 0.78 \\
\hline & My voice assistant is quite competent & 0.86 \\
\hline & I feel attached to my voice assistant & 0.78 \\
\hline & I feel delighted while interacting with my voice assistant & 0.77 \\
\hline & My voice assistant is quite intelligent & 0.68 \\
\hline & I find my voice assistant to be often sensitive to my needs & 0.66 \\
\hline \multirow{4}{*}{$\begin{array}{l}\text { Social identity (SI) } \\
{[4],[30]}\end{array}$} & The use of voice assistants among people around me is growing fast & 0.76 \\
\hline & I have heard a lot about the features and benefits of using voice assistants & 0.72 \\
\hline & People I know will appreciate the fact that I use a voice-assistants & 0.69 \\
\hline & I get a lot of encouragement from people around me for using my voice assistant & 0.71 \\
\hline \multirow[t]{4}{*}{ Convenience (CV) [75] } & It is more convenient for me to complete tasks just with a voice command & 0.90 \\
\hline & Voice assistant allows multi-tasking & 0.86 \\
\hline & I like the ability of my voice assistant to save my time and effort in doing things & 0.84 \\
\hline & Interacting with the voice assistant is easy and clearly understandable & 0.80 \\
\hline \multirow[t]{6}{*}{ Perceived Usefulness (PU) [1], [4] } & Using voice assistant in my work enables me to accomplish my tasks more quickly. & 0.87 \\
\hline & Using voice assistant improves my work performance. & 0.85 \\
\hline & Using voice assistant is useful in my daily life. & 0.88 \\
\hline & I find voice assistant more helpful than sales agents & 0.82 \\
\hline & Using voice assistant is a more efficient way of working & 0.78 \\
\hline & Using voice assistant improves my work experience & 0.72 \\
\hline \multirow[t]{5}{*}{ Perceived Playfulness (PP) [30] } & Voice assistant makes the work more interesting and playful & 0.88 \\
\hline & Using voice assistant is satisfying. & 0.88 \\
\hline & The engagement I have with a voice assistant is always meaningful & 0.78 \\
\hline & I am always curious to use my voice-assistant and do new things with it & 0.85 \\
\hline & I actively look forward to using instances where I can use a voice assistant. & 0.76 \\
\hline
\end{tabular}




\begin{tabular}{|l|l|c|}
\hline Information Search (IS) [20] & I commonly use voice-assistant to search for information & 0.81 \\
\cline { 2 - 3 } & Voice assistant is a helpful learning tool. & 0.74 \\
\cline { 2 - 3 } & I regularly ask questions to my voice-assistant & 0.75 \\
\hline Task Function (TS) & I use voice assistant regularly to play music & 0.92 \\
\cline { 2 - 3 } & I use the voice assistant to place order online & 0.86 \\
\cline { 2 - 3 } & I use the voice assistant to control my smart devices. & 0.71 \\
\cline { 2 - 3 } & Voice assistant is now an important tool for me, and I rely a lot on my voice assistant & 0.75 \\
\hline
\end{tabular}

*All the study measures including their measurement items are developed from the qualitative study and past literature 
Table 5. Model fit indices

\begin{tabular}{|l|c|c|c|}
\hline \multicolumn{1}{|c|}{ The goodness of fit measures } & Recommended valt & $\begin{array}{c}\text { Structural } \\
\text { model }\end{array}$ & Measurement mo \\
\hline Chi-square/degree of freedom & $\leq 3.00$ & 2.43 & 1.45 \\
\hline Goodness-of-fit (GFI) & $\geq 0.90$ & 0.97 & 0.90 \\
\hline Adjusted goodness-of-fit (AGFI) & $\geq 0.80$ & 0.91 & 0.88 \\
\hline Normalized fit index (NFI) & $\geq 0.90$ & 0.96 & 0.92 \\
\hline Comparative fit index (CFI) & $\geq 0.90$ & 0.97 & 0.97 \\
\hline Root mean square error of approximation (RMSEA) & $\leq 0.10$ & 0.04 & 0.03 \\
\hline Tucker-Lewis fit index (TLI) & $\geq 0.90$ & 0.93 & 0.97 \\
\hline
\end{tabular}

A Satisfactory model fit was obtained, both standardized factor loadings of items and AVE values of the constructs were greater than 0.50 and $\mathrm{CR}$ values greater than 0.70 hence, the convergent validity was established [76], [77]. All constructs displayed high levels of reliability (0.80 or higher) [76]. Discriminant validity was established since the AVE values of the constructs were greater than the squared inter factor correlations (Table 6).

Table 6. Validity and reliability estimates

\begin{tabular}{|c|c|c|c|c|c|c|c|c|c|c|c|c|c|}
\hline & $\overline{\mathbf{X}}$ & $\boldsymbol{\sigma}$ & CR & AVE & MSV & ASV & SI & PU & PP & PR & $\mathrm{CV}$ & TF & IS \\
\hline SI & 2.72 & 0.66 & 0.81 & 0.52 & 0.16 & 0.11 & 0.72 & & & & & & \\
\hline PU & 3.97 & 0.57 & 0.93 & 0.68 & 0.30 & 0.18 & 0.32 & 0.82 & & & & & \\
\hline $\mathbf{P P}$ & 3.63 & 0.75 & 0.92 & 0.69 & 0.29 & 0.18 & 0.31 & 0.48 & 0.83 & & & & \\
\hline PR & 3.15 & 0.74 & 0.91 & 0.59 & 0.29 & 0.16 & 0.39 & 0.36 & 0.54 & 0.77 & & & \\
\hline $\mathrm{CV}$ & 2.15 & 0.71 & 0.93 & 0.73 & 0.16 & 0.09 & 0.40 & 0.23 & 0.23 & 0.39 & 0.86 & & \\
\hline TF & 4.04 & 0.65 & 0.89 & 0.67 & 0.41 & 0.16 & 0.17 & 0.51 & 0.36 & 0.26 & 0.23 & 0.82 & \\
\hline IS & 4.77 & 0.48 & 0.81 & 0.59 & 0.41 & 0.22 & 0.31 & 0.55 & 0.51 & 0.43 & 0.22 & 0.64 & 0.77 \\
\hline
\end{tabular}

Bold values on diagonal $=$ SQRT $(A V E)$, off-diagonal $=$ correlation coefficients, composite reliability (CR), average variance extracted (AVE), maximum shared variance (MSV), average shared variance (ASV), SI-social identity, PUperceived usefulness, PP-perceived playfulness, PR-personification, CV-convenience, TF-task function, IS-information search

\subsection{Common method bias}

Data collected for the study were vulnerable to common method bias since it includes self-reported behavioral constructs [78]. Hence, we attempt to address the issue by using a multi-pronged approach, as suggested by Chang et al. [79]. First, we randomized the questionnaire items, and efforts were made to reduce ambiguity in the instrument [80]. Second, respondents were informed that the purpose of the study is academic, and their identity would remain anonymous. We also informed respondents that there is no right or wrong answer, and we were interested in only knowing their perception about the various aspects of using voice-assistants [78]. On completion of data collection, we conducted post hoc Harman's Single Factor test, and it was found that the total explained variance by the single factor was 
$30.29 \%$, which was well below the cut off value of $50 \%$ [81]. Finally, we included a common latent factor, and no common method bias was observed. Therefore, we assume that common method variance is absent, and further correction for the common method variance while testing the structural model was not required.

\subsection{Structural model}

The research model (Figure 3) was empirically validated using the SEM equation with the maximum likelihood method. The results indicate a model fit with acceptable indicators. The chi-square was significant $\left(\square^{2}=133.79, d f=55, p=0.00, \square^{2} / d f=2.43\right)$. The other model fit indices such as root mean square error of approximation $(R M S E A=0.04)$, comparative fit index $(C F I=0.97)$, TuckerLewis fit index $(T L I=0.93)$, were observed as per the recommended cut-off values [73], [82], [83].

Figure 3. Structural Model

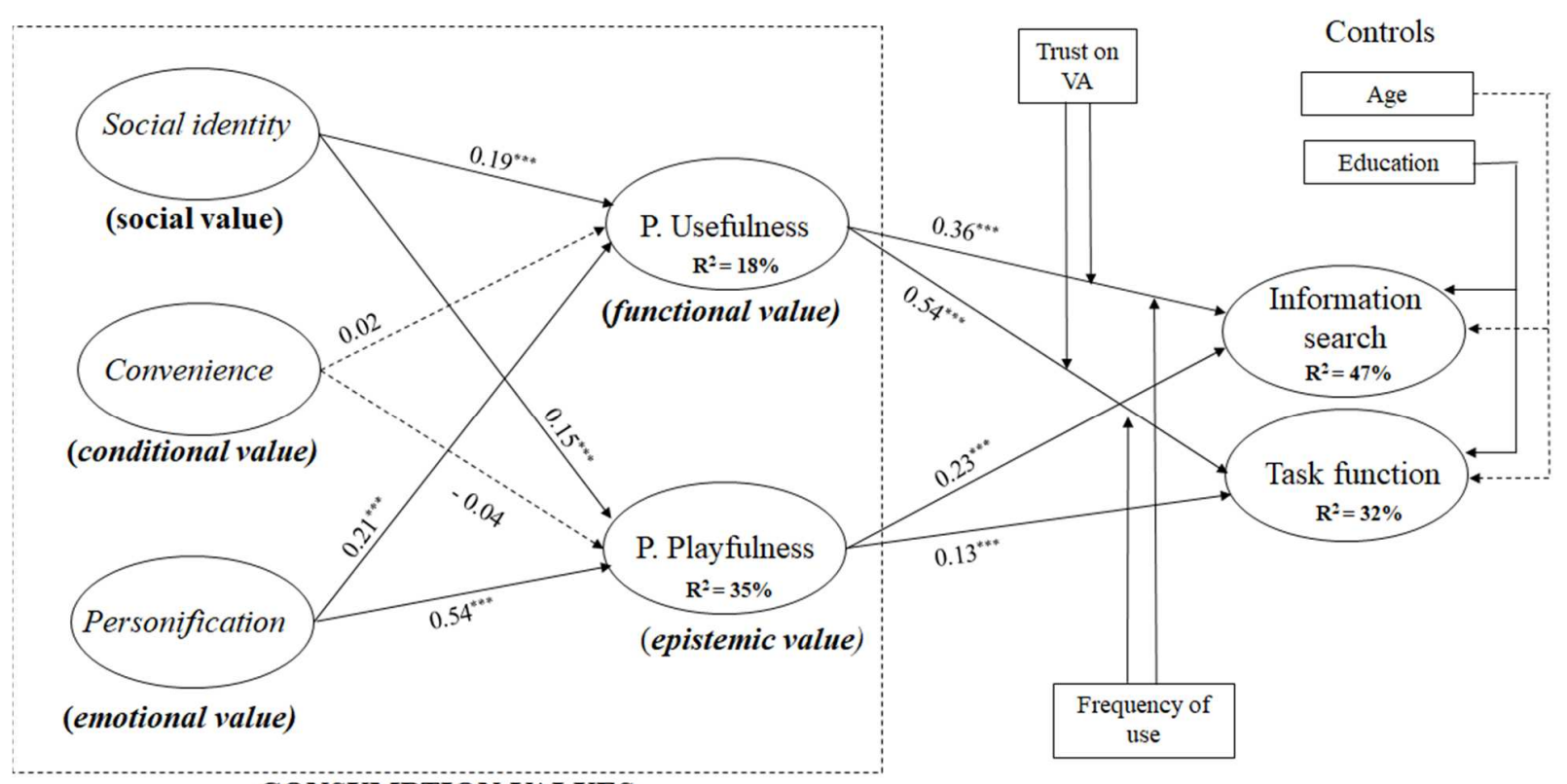

\section{CONSUMPTION VALUES}

All hypotheses barring $\mathrm{H} 4 \mathrm{a}$ and $\mathrm{H} 4 \mathrm{~b}$ were supported (Figure 3). It was observed that while social identity is positively associated with perceived usefulness $\left(\beta=0.21, p<0.001^{* * *}\right)$ and perceived playfulness $\left(\beta=0.12, p<0.01^{* *}\right)$, it has a direct association with information $\operatorname{search}(\beta=0.02, p<$ $\left.0.001^{* * *}\right)$. Personification positively affected perceived usefulness $\left(\beta=0.27, p<0.001^{* * * *}\right)$ and perceived playfulness $\left(\beta=0.27, p<0.001^{* * *}\right)$. Perceived usefulness was positively associated with 
both information search $\left(\beta=0.39, p<0.001^{* * *}\right)$ as well as task function $\left(\beta=0.46, p<0.001^{* * *}\right)$. Similarly, perceived playfulness was positively associated with both information search $(\beta=0.26, p<$ $\left.0.001^{* * *}\right)$ and task function $\left(\beta=0.13, p<0.001^{* * *}\right)$.

\subsection{Moderators and control variables}

The moderating effect of frequency of use and trust on outcome variables were examined using the Hayes process macro method [84]. We used 5000 bootstrap samples at a confidence interval of 95 percent to assess the moderating effect. We present the visualization of moderation effects in Figure 4. Frequency of use significantly moderates the association between perceived usefulness and information search $(\beta=.08, p<.05, C I[.038-0.113])$, task function $(\beta=.07, p<.05, C I[.019-$ 0.128]). The frequency of use had no moderation effect between playfulness and usage of voiceassistants. Trust moderated the association between perceived usefulness and usage of voice-assistants i.e., task function $(\beta=0.10, p<.001, C I[.002-.193])$, and information search $(\beta=0.08, p<.001, C I$ $[.019-.148])$.

Figure 4 (a). Moderating effects - Trust x usefulness
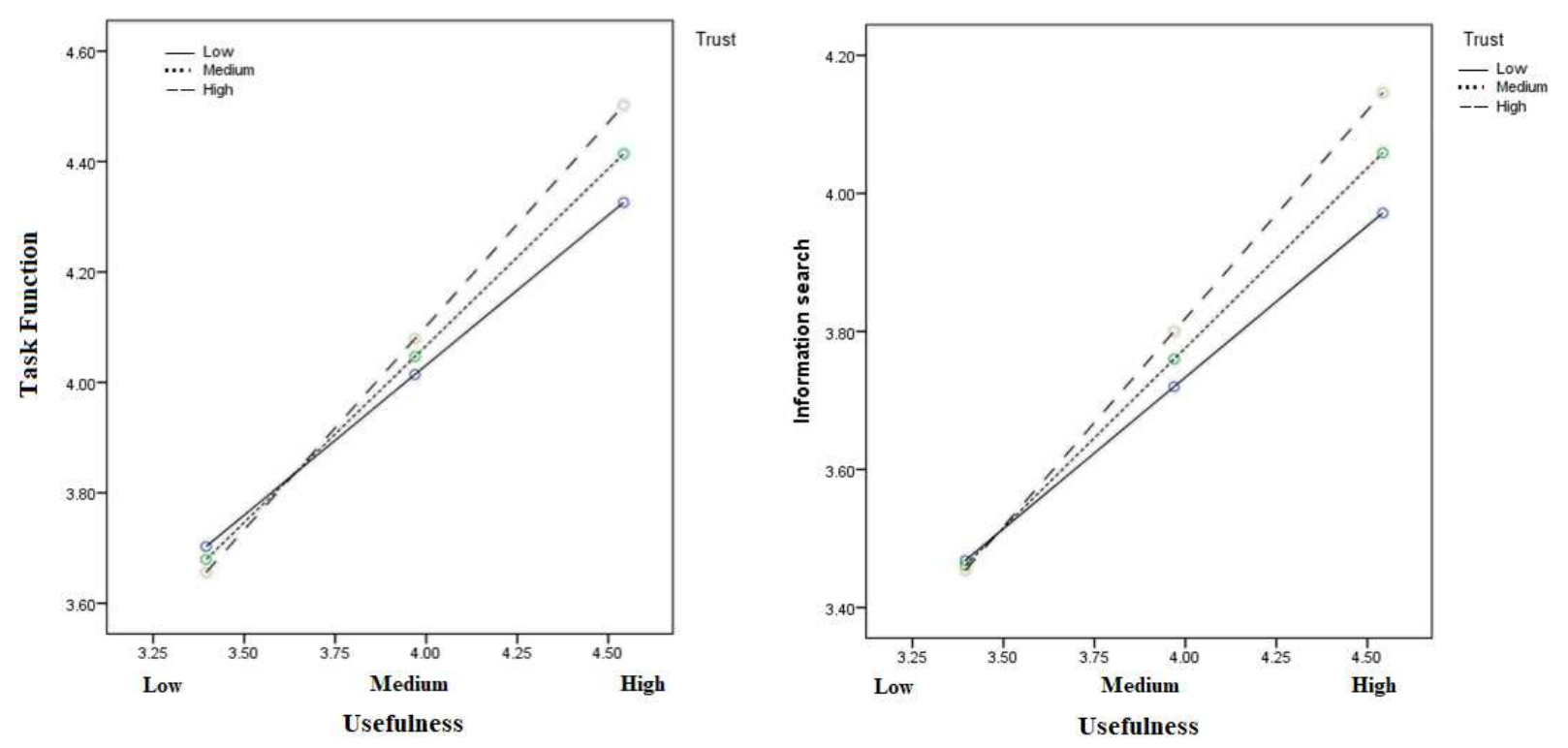
Figure 4 (b). Moderating effects - Frequency of use x usefulness
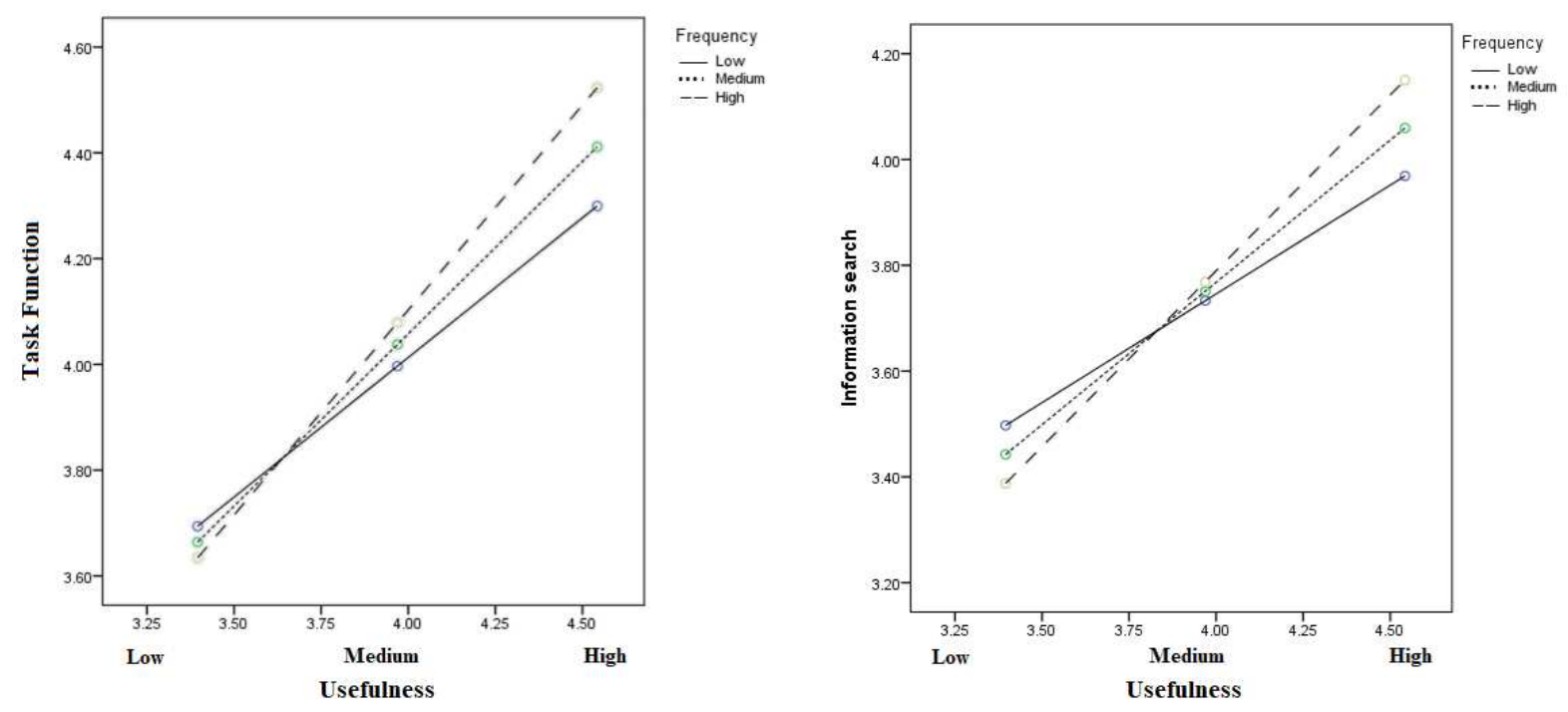

We controlled for age and education and results indicated insignificant confounding effect of age however, education significantly controlled the outcome variables. The findings are consistent with the prior literature [4].

\section{Discussion}

We made a systematic attempt to understand how consumption values drive the usage of voiceassistants for various purposes and how these consumption values are interrelated. We adopted a mixed-method approach to answering the above questions. First, we used a qualitative study to identify the consumption values relevant to the context of voice-assistants - social identity, personification, convenience, perceived usefulness, and perceived playfulness. The qualitative study also helped us identify the measurement items for the above constructs. Thereafter, an extensive review of literature helped us construct hypotheses, and the proposed relationships were empirically investigated by measuring the constructs using an online survey panel. The research findings reveal that except H4a and $\mathrm{H} 4 \mathrm{~b}$, all other hypotheses were empirically supported.

It was found that perceived usefulness and perceived playfulness shared a significant positive association with information search and task function ( $\mathrm{H} 1 \& \mathrm{H} 2)$. Consumers appreciate the ability of voice-assistants to generate pleasurable experiences as it helps consumers to satisfy their hedonic motives. Therefore, the higher the playfulness, the more likely consumers are to use their voice- 
assistants. Similarly, consumers perceive their voice-assistants to be useful and due to which, they are likely to use them for both information search and task function.

The H3 was supported which suggests that social identity, an important consumption value, was positively associated with usefulness and playfulness. The study results suggests that consumers are motivated to use voice-assistants as it provides them with an opportunity to express their social identity in a digitally dominated social environment. Furthermore, the consumers connect with the voiceassistants as their need for self-expression is satisfied. Due to these reasons, consumers consider the use of voice-assistants as useful and playful. This finding is in line with the observations of Ogbanufe and Gerhart [46] in the context of a smartwatch

The H4 was not supported as study results suggest that conditional value, i.e., convenience, is not associated with perceived usefulness ( $\mathrm{H} 4 \mathrm{a})$ and perceived playfulness ( $\mathrm{H} 4 \mathrm{~b})$. This finding is consistent with the arguments of Park and Lee [39] who found that conditional value to be inappropriate in the context of online games. Similarly, Turel et al. [30] also dropped conditional value from the research framework while examining the behavioral intentions to use digital artefacts. In the context of voice-assistants, convenience is an inherent characteristic, and hence consumers can use their voiceassistants at any time. Other possible reason could be that although the voice-assistants are becoming popular, the awareness about the full potential functions and specifications of voice assistants is extremely low among users. Due to which, the respondents in the current study failed to fully envision the conditions under which voice-assistants can create additional convenience. As a result, convenience was not a significant value component for the existing users in this study.

The H5 was supported, which suggest that personification consumption value is positively associated with perceived usefulness (H5a) and perceived playfulness (H5b). Humanization of voice assistants (e.g., Alexa and Siri) in a conversation such as greeting its users with "good morning", "have a good day" etc. reinforces its personification, to which the consumers reciprocate by saying "thank you" to their voice-assistants, hence making them playful. This implies that personification enhances the interaction between consumers and their voice-assistants and result in playfulness [60]. Furthermore, in the pursuit of interacting with an intelligent voice-assistant, consumers obtain a feeling of extending themselves and enjoy the control they exercise on their voice-assistants as a master or a companion [9]. Due to this, consumers find voice-assistants as useful.

The support for H3 and H5 clearly suggest that the consumption values were inter-related, and they share positive associations, something which is rarely studied in the prior extended literature. 
The study results confirmed the significant positive moderating impact of trust (H6) and frequency of use $(\mathrm{H} 7)$ on the association of perceived usefulness with information search and task function. To the best of the authors' knowledge, none of the existent studies have examined the trust and frequency of use as a moderator in the context of voice-assistants or digital artefacts. Consequently, there is no a priori to the study findings with respect to the findings concerning the moderating variables. In our study, we found through the qualitative interviews that consumers are comfortable trusting their voice assistants for shopping grocery and pizza. When consumers place high trust on their voice assistants than they are more likely to use them for information search and task functions, due to which, they are more likely to consider them as useful. Furthermore, qualitative interviews have also suggested that if consumers perceive high risk (i.e., low trust) in using voice-assistants than they are less likely to engage in information search as well as task function.

\subsection{Theoretical Implications}

This study makes four major contributions to the existing literature. First, voice-assistants are increasingly becoming popular, and their penetration is expected to grow exponentially. However, a little is known about the underlying behavioral dimensions that drive the usage of voice-assistants. This study aims to bridge the existing gap and attempts to further our understanding of consumer behavior in the context of this new technology that is highly interactive.

Second, it is the first study to adopt the TCV framework and empirically extend the generic values in the context of voice-assistant to gain a better understanding of the consumption values that drivers the usage of voice-assistants. Therefore, the research framework presented in the study and the empirical validation offers a unique contribution enhancing our understanding of consumer behavior in the context of voice-technology. The extension of the generic values [16], [17] and identification of the measurement items for extended constructs using a mixed-methods approach is a noteworthy contribution of this study. Furthermore, the study contributes to the TCV framework [15] by not only contextualizing and extending it for voice-assistants but also finds empirical support that the five consumption values are not at the same level rather, they are interrelated.

Third, this study identifies and validates the moderating influence of trust and frequency of use. The previous research has drawn attention towards the trust issues associated with digital technology and consumers' intention to use such technology [5]. While the existing literature remains unequivocal [85] about the role of trust, this study observed that high trust strengthens the association between 
consumption values and information search. Further, this is the first study to add trust as a moderating factor to the TCV framework.

Finally, this study enhances the limited understanding of the consumption values of voiceassistant users. The study covers a broad sample of encompassing users from the USA, Europe, and India; hence, the results are generalizable in a larger context.

\subsection{Managerial implications}

The findings of this study offer several managerial implications for technology providers and marketers. This research will benefit the developers of voice-assistants as they can focus on integrating the consumption values that are derived by the consumers using voice-assistants. With the continuous development in deep learning, neural network algorithms, natural language processing, and AI the producers of voice-assistants can enhance the human-like qualities of voice-assistants, i.e., focus on personification value which will further increase the usage of voice-assistants by the consumers. Similarly, social identity is reported to influence perceived usefulness, perceived playfulness as well as information search. Therefore, the technology providers and marketers can engage various influencers and opinion leaders such as celebrities and utilize them for endorsing the voice-assistants.

The study further finds that consumers use voice-assistants for two major purposes, i.e., information search and task function. Therefore, not only the producers of voice-assistants but also other marketers can focus on optimizing their online content that is searchable by voice-assistants. Additionally, marketers must reconsider their SEO algorithms and create content strategies that can boost SEO in the context of search queries raised on voice-assistants. Brands can use the insights from this study to create effective voice search strategies that can help them offer unique and personalized consumer experiences.

The study findings reveal that consumers using their voice-assistants for performing tasks such as controlling IoT devices, placing online orders, etc., are influenced by both perceived usefulness and perceived playfulness. Therefore, the developers working on designing applications for voiceassistants should focus on developing skills in voice-assistants that meet the task completion needs of consumers. For example, a home appliance firm can integrate intelligent voice skills in their devices based on the five consumption values discussed in this study.

This study reveals that trust is an important concern for users and consumers to perceive their voiceassistants to be intrusive. According to the empirical evidence, trust has a significant negative influence 
on the information search. Therefore, the producers of voice-assistants must focus on taking necessary measures that can reassure consumers about the non-intrusiveness of voice-assistants and develop effective communication campaigns to convince consumers that their search queries remain confidential.

\subsection{Conclusion, Limitations and future research}

Consumption values can facilitate the adoption and continuous usage of voice-assistants. Prior literature argues that consumption values derive from the usage of digital artefacts. However, it lacked evidence in the context of voice-assistants. This study makes the first attempt to bridge this gap in proposing a consumption value based theoretical model and validating it with the active users of voiceassistants across three continents. This study had attempted to extend the TCV literature and further our understanding of consumer behavior in the context of voice-assistants [86], [87]. The study has examined a) the association between the consumption values, b) the association of perceived usefulness and perceived playfulness with the usage of voice-assistants, i.e., information search and task function, and c) the moderating effect of trust and frequency of use on the associations shared between perceived usefulness and the usage of voice-assistants.

The present study has some limitations that can be addressed in future studies. First, in this study, we limit our analysis from the perspective of consumption values. However, future studies can use a different approach, such as stimulus-organism-response (SOR) [88], [89] and behavioral reasoning theory (BRT) [90], [91], to provide an alternative explanation of consumer behavior in the context of voice-assistants. Second, we classify the behavior into two categories of usage. Future research studies can further classify the usage of voice-assistants on a different parameter such as transactional vs non-transactional usage, and it would be interesting to know how consumption values influence user behavior under a new classification. Third, the current study has included only two types of moderating variables. In future studies, scholars can include additional moderating variables to capture how consumer behavior changes in the light of new moderators. Example, it will be interesting to know how the users and non-users of voice-assistants differ from each other. Fourth, the current study suffers from a methodological limitation that it has used a cross-sectional data which is a selfreported research design, due to which, causality between study variables cannot be established. Due to this, scholars can utilize longitudinal designs to understand how behavior gets modified over a 
certain period of ownership. Furthermore, experiments can be conducted to study the causality between the key variables.

\section{References}

[1] Moriuchi, E. (2019). Okay, Google!: An empirical study on voice assistants on consumer engagement and loyalty. Psychology \& Marketing, 36(5), 489-501.

[2] Karnouskos, S. (2018). Self-driving car acceptance and the role of ethics. IEEE Transactions on Engineering Management, 67(2), 252-265.

[3] Feng, H., Fawaz, K., \& Shin, K. G. (2017, October). Continuous authentication for voice assistants. In Proceedings of the 23rd Annual International Conference on Mobile Computing and Networking (pp. 343-355).

[4] McLean, G., \& Osei-Frimpong, K. (2019). Hey Alexa... examine the variables influencing the use of artificial intelligent in-home voice assistants. Computers in Human Behavior, 99, 28-37.

[5] Hoy, M. B. (2018). Alexa, Siri, Cortana, and more: an introduction to voice assistants. Medical Reference Services Quarterly, 37(1), 81-88.

[6] Smith, K. T. (2020). Marketing via smart speakers: what should Alexa say? Journal of Strategic Marketing, 28(4), 350-365.

[7] Burbach, L., Halbach, P., Plettenberg, N., Nakayama, J., Ziefle, M., \& Valdez, A. C. (2019, July). " Hey, Siri"," Ok, Google"," Alexa". Acceptance-Relevant Factors of Virtual Voice-Assistants. In 2019 IEEE International Professional Communication Conference (ProComm) (pp. 101-111). IEEE.

[8] Stenvanovic, I (2020). 41 voice search statistics you need to hear in 2020. Kommando tech. Accessed on 02 August, 2020. https://kommandotech.com/statistics/voice-search-statistics/

[9] Schweitzer, F., Belk, R., Jordan, W., \& Ortner, M. (2019). Servant, friend or master? The relationships users build with voice-controlled smart devices. Journal of Marketing Management, 35(7-8), 693-715

[10] McCaffrey, M., Hayes, P., Wagner, J., \& Hobbs, M., (2018). Consumer Intelligence Series: Prepare for the voice revolution, PwC, USA, Accessed on July 13, 2019 [Online]. Available at https://www.pwc.com/us/en/advisory-services/publications/consumer-intelligence-series/voiceassistants.pdf

[11] Lei, X., Tu, G. H., Liu, A. X., Li, C. Y., \& Xie, T. (2018, May). The insecurity of home digital voice assistants-vulnerabilities, attacks and countermeasures. In 2018 IEEE Conference on Communications and Network Security (CNS) (pp. 1-9). IEEE.

[12] Kinsella, B. (2019). Google Again Leads in Voice Assistant IQ Test but Alexa is Closing the Gap According to Loup Ventures. Accessed on August 09, 2020 https://voicebot.ai/voice-assistantseo-report-for-brands/ 
[13] Klaus, P., \& Zaichkowsky, J. (2020). AI voice bots: services marketing research agenda. Journal of Services Marketing. 34(3), 389-398.

[14] Kaplan, A., \& Haenlein, M. (2019). Siri, Siri, in my hand: Who's the fairest in the land? On the interpretations, illustrations, and implications of artificial intelligence. Business Horizons, 62(1), $15-25$.

[15] Sheth, J. N., Newman, B. I., \& Gross, B. L. (1991). Why we buy what we buy: A theory of consumption values. Journal of Business Research, 22(2), 159-170.

[16] Talwar, S., Dhir, A., Kaur, P., \& Mäntymäki, M. (2020). Why do people purchase from online travel agencies (OTAs)? A consumption values perspective. International Journal of Hospitality Management, 88, 102534.

[17] Mäntymäki, M., Islam, A. N., \& Benbasat, I. (2020). What drives subscribing to premium in freemium services? A consumer value $\square$ based view of differences between upgrading to and staying with premium. Information Systems Journal, 30(2), 295-333.

[18] Sedano, T., Ralph, P., \& Peraire, C. (2020). Dual-Track Development. IEEE Software, 37(6), 5864.

[19] Martin, J., Mortimer, G., \& Andrews, L. (2015). Re-examining online customer experience to include purchase frequency and perceived risk. Journal of retailing and consumer services, 25 , 81-95.

[20] Venkatesh, V., Thong, J. Y., \& Xu, X. (2012). Consumer acceptance and use of information technology: extending the unified theory of acceptance and use of technology. MIS Quarterly, 157-178.

[21] Yang, H., \& Lee, H. (2018). Exploring user acceptance of streaming media devices: an extended perspective of flow theory. Information Systems and e-Business Management, 16(1), 1-27.

[22] Boonrod, A., \& Ketavan, P. (2018). The Future Is Voice. Research World, 2018(71), 40-45.

[23] Boyle, B. (2017). What is Siri? Apple's personal voice assistant explained - Pocket-lint. Pocketlint.com. Retrieved 25 November 2019, from http://www.pocket-lint.com/news/112346what-is-siriapple-s-personal-voice-assistant-explained

[24] Laukkanen, T. (2016). Consumer adoption versus rejection decisions in seemingly similar service innovations: The case of the Internet and mobile banking. Journal of Business Research, 69(7), 2432-2439.

[25] Bagozzi, R. P. (2007). The legacy of the technology acceptance model and a proposal for a paradigm shift. Journal of the association for information systems, 8(4), 3.

[26] Van Raaij, E. M., \& Schepers, J. J. (2008). The acceptance and use of a virtual learning environment in China. Computers \& education, 50(3), 838-852.

[27] Guzman, A. L. (2019). Voices in and of the machine: Source orientation toward mobile virtual assistants. Computers in Human Behavior, 90, 343-350. 
[28] Zhang, J., \& Mao, E. (2012). What's around me?: Applying the theory of consumption values to understanding the use of location-based services (LBS) on smart phones. International Journal of E-Business Research (IJEBR), 8(3), 33-49.

[29] Chen, T. Y., Liu, Y. C., \& Chen, Y. M. (2013, December). Research on product common attribute model with consumption value theory applied in food industry. In 2013 IEEE International Conference on Industrial Engineering and Engineering Management (pp. 447-451). IEEE.

[30] Turel, O., Serenko, A., \& Bontis, N. (2010). User acceptance of hedonic digital artifacts: A theory of consumption values perspective. Information \& Management, 47(1), 53-59.

[31] Hajli, N., Wang, Y., Tajvidi, M., \& Hajli, M. S. (2017). People, technologies, and organizations interactions in a social commerce era. IEEE Transactions on Engineering Management, 64(4), 594-604.

[32] Petrovčiková, K., \& Sudzina, F. (2018). Smartphone adoption: Design of factors within the framework of Theory of Consumption Values. In Consumer Behavior, Organizational Strategy and Financial Economics (pp. 53-62). Springer, Cham.

[33] Youn, S. Y., \& Lee, K. H. (2019). Proposing value-based technology acceptance model: testing on paid mobile media service. Fashion and Textiles, 6(1), 13.

[34] Park, K., Kwak, C., Lee, J., \& Ahn, J. H. (2018). The effect of platform characteristics on the adoption of smart speakers: empirical evidence in South Korea.Telematics and Informatics, 35(8), 2118-2132.

[35] Pal, D., Arpnikanondt, C., Funilkul, S., \& Varadarajan, V. (2019, July). User experience with smart voice assistants: the accent perspective. In 2019 IEEE, 10th International Conference on Computing, Communication and Networking Technologies (ICCCNT) (pp. 1-6). IEEE.

[36] Kowalczuk, P. (2018). Consumer acceptance of smart speakers: a mixed-methods approach. Journal of Research in Interactive Marketing. 12(4), 418-431.

[37] Yang, H., \& Lee, H. (2019). Understanding user behavior of virtual personal assistant devices. Information Systems and e-Business Management, 17(1), 65-87.

[38] Mäntymäki, M., \& Salo, J. (2015). Why do teens spend real money in virtual worlds? A consumption values and developmental psychology perspective on virtual consumption. International Journal of Information Management, 35(1), 124-134.

[39] Park, B. W., \& Lee, K. C. (2011). Exploring the value of purchasing online game items. Computers in Human Behavior, 27(6), 2178-2185.

[40] Ahn, T., Ryu, S., \& Han, I. (2007). The impact of Web quality and playfulness on user acceptance of online retailing. Information \& management, 44(3), 263-275.

[41] Yang, S., Wang, B., \& Lu, Y. (2016). Exploring the dual outcomes of mobile social networking service enjoyment: The roles of social self-efficacy and habit. Computers in Human Behavior, 64, 486-496.

[42] Sledgianowski, D., Kulviwat, S.: Using social network sites: The effects of playfulness, critical mass and trust in a hedonic context. Journal of Computer Information Systems, 49, 74-83 (2009) 
[43] He, H., Li, Y., \& Harris, L. (2012). Social identity perspective on brand loyalty. Journal of Business Research, 65(5), 648-657.

[44] McGowan, M., Shiu, E., \& Hassan, L. M. (2017). The influence of social identity on value perceptions and intention. Journal of Consumer Behavior, 16(3), 242-253.

[45] Bødker, M., Gimpel, G., \& Hedman, J. (2009). The user experience of smart phones: a consumption values approach. Proceedings the 8th Global Mobility Roundtable: Transformation Through Mobility, GMR, Cairo, Egypt

[46] Ogbanufe, O., \& Gerhart, N. (2020). The mediating influence of smartwatch identity on deep use and innovative individual performance. Information Systems Journal. https://doi.org/10.1111/isj.12288

[47] Hsiao, K. L., \& Chen, C. C. (2018). What drives smartwatch purchase intention? Perspectives from hardware, software, design, and value. Telematics and Informatics, 35(1), 103-113.

[48] Liu, Y., \& Han, M. (2020). Determining the Key Factors of Wearable Devices Consumers' Adoption Behavior Based on an MADM Model for Product Improvement. IEEE Transactions on Engineering Management.

[49] Liu, J., Thomas, J. M., \& Higgs, S. (2019). The relationship between social identity, descriptive social norms and eating intentions and behaviors. Journal of Experimental Social Psychology, 82, 217-230.

[50] Sierra, J. J., \& McQuitty, S. (2007). Attitudes and emotions as determinants of nostalgia purchases: An application of social identity theory. Journal of Marketing Theory and Practice, 15(2), 99-112.

[51] Hsieh, S. H., \& Tseng, T. H. (2017). Playfulness in mobile instant messaging: Examining the influence of emoticons and text messaging on social interaction. Computers in Human Behavior, 69, 405-414.

[52] Dunn, R. A., \& Guadagno, R. E. (2012). My avatar and me-Gender and personality predictors of avatar-self discrepancy. Computers in Human Behavior, 28(1), 97-106.

[53] Hur, W. M., Yoo, J. J., \& Chung, T. L. (2012). The consumption values and consumer innovativeness on convergence products. Industrial Management \& Data Systems, 112, 688-706.

[54] Chang, C. C., Liang, C., Yan, C. F., \& Tseng, J. S. (2013). The impact of college students' intrinsic and extrinsic motivation on continuance intention to use English mobile learning systems. The Asia-Pacific Education Researcher, 22(2), 181-192.

[55] Strayer, D. L., Cooper, J. M., Turrill, J., Coleman, J. R., \& Hopman, R. J. (2017). The smartphone and the driver's cognitive workload: A comparison of Apple, Google, and Microsoft's intelligent personal assistants. Canadian Journal of Experimental Psychology/Revue canadienne de psychologie expérimentale, 71(2), 93.

[56] Chung, J., \& Tan, F. B. (2004). Antecedents of perceived playfulness: an exploratory study on user acceptance of general information-searching websites. Information \& Management, 41(7), 869-881.

[57] Yu, C. E. (2020). Humanlike robots as employees in the hotel industry: Thematic content analysis of online reviews. Journal of Hospitality Marketing \& Management, 29(1), 22-38. 
[58] Purington, A., Taft, J. G., Sannon, S., Bazarova, N. N., \& Taylor, S. H. (2017, May). " Alexa is my new BFF" Social Roles, User Satisfaction, and Personification of the Amazon Echo. In Proceedings of the 2017 CHI Conference Extended Abstracts on Human Factors in Computing Systems (pp. 2853-2859).

[59] Yuan, Y., Thompson, S., Watson, K., Chase, A., Senthilkumar, A., Brush, A. B., \& Yarosh, S. (2019). Speech interface reformulations and voice assistant personification preferences of children and parents. International Journal of Child-Computer Interaction, 21, 77-88.

[60] Pradhan, A., Findlater, L., \& Lazar, A. (2019). " Phantom Friend" or" Just a Box with Information" Personification and Ontological Categorization of Smart Speaker-based Voice Assistants by Older Adults. Proceedings of the ACM on Human-Computer Interaction, 3(CSCW), 1-21.

[61] Park, J., \& Yang, S. (2006). The moderating role of consumer trust and experiences: Value driven usage of mobile technology. International Journal of Mobile Marketing, 1(2).

[62] Chung, N., Song, H. G., \& Lee, H. (2017). Consumers' impulsive buying behavior of restaurant products in social commerce. International Journal of Contemporary Hospitality Management. 29(2), 709-731.

[63] Wells, A., Usman, A. B., \& McKeown, J. (2020). Trusting Smart Speakers: Understanding the Different Levels of Trust between Technologies. International Journal of Computer Science and Security, 14(2), 72-81.

[64] Lankton, N. K., McKnight, D. H., \& Tripp, J. F. (2019). Understanding the antecedents and outcomes of Facebook privacy behaviors: an integrated model. IEEE Transactions on Engineering Management, 67(3), 697-711.

[65] Hansen, J. M., Saridakis, G., \& Benson, V. (2018). Risk, trust, and the interaction of perceived ease of use and behavioral control in predicting consumers' use of social media for transactions. Computers in Human Behavior, 80, 197-206.

[66] Föhr, J., \& Germelmann, C. C. (2019). Alexa, who are you? Consumer trust in and mental representations of smart home technologies. International Conference on Challenges in Managing Smart Products and Services (CHIMSPAS), 22.-23.08.2019, Bielefeld. Accessed on August 09, 2020 https://eref.uni-bayreuth.de/id/eprint/53372

[67] Natarajan, T., Balasubramanian, S. A., \& Kasilingam, D. L. (2017). Understanding the intention to use mobile shopping applications and its influence on price sensitivity. Journal of Retailing and Consumer Services, 37, 8-22.

[68] Chen, C. (2013). Perceived risk, usage frequency of mobile banking services. Managing Service Quality: An International Journal, 23 (5), 410-436.

[69] Baptista, G., \& Oliveira, T. (2015). Understanding mobile banking: The unified theory of acceptance and use of technology combined with cultural moderators. Computers in Human Behavior, 50, 418-430.

[70] Dhir, A., Chen, G. M., \& Chen, S. (2017). Why do we tag photographs on Facebook? Proposing a new gratifications scale. new media \& society, 19(4), 502-521. 
[71] Cohen, J. (1968). Weighted kappa: nominal scale agreement provision for scaled disagreement or partial credit. Psychological Bulletin, 70(4), 213.

[72] Anderson, J. C., \& Gerbing, D. W. (1988). Structural equation modeling in practice: A review and recommended two-step approach. Psychological Bulletin, 103(3), 411.

[73] Hair, J. F., Ringle, C. M., \& Sarstedt, M. (2011). PLS-SEM: Indeed a silver bullet. Journal of Marketing Theory and Practice, 19(2), 139-152.

[74] Wang, W. (2017). Smartphones as social actors? Social dispositional factors in assessing anthropomorphism. Computers in Human Behavior, 68, 334-344.

[75] Xiao, X., Hedman, J., \& Runnemark, E. (2015). Use of payment technology: A perspective based on theory of consumption value. ECIS 2015 Research-in-Progress Papers. Paper 40.

[76] Fornell, C., \& Larcker, D. F. (1981). Structural equation models with unobservable variables and measurement error: Algebra and statistics. 18(3), 382-388

[77] Hair, J. F., Anderson, R. E., Tatham, R. L., \& William, C. (1998). Black (1998), Multivariate data analysis. Upper Saddle River, NJ: Prentice Hall.

[78] Podsakoff, P. M., MacKenzie, S. B., Lee, J. Y., \& Podsakoff, N. P. (2003). Common method biases in behavioral research: a critical review of the literature and recommended remedies. Journal of applied psychology, 88(5), 879.

[79] Chang, F., Qiu, W., Zamar, R. H., Lazarus, R., \& Wang, X. (2010). Clues: an R package for nonparametric clustering based on local shrinking. Journal of Statistical Software, 33(4), 1-16.

[80] Kaushik, A. K., \& Rahman, Z. (2015). An alternative model of self-service retail technology adoption. Journal of Services Marketing. 29(5), 406-420.

[81] Harman, D. (1967). A single factor test of common method variance. Journal of Psychology, 35(1967), 359-378.

[82] Browne, M. W., Cudeck, R., (1993). Alternative ways of assessing model fit. In Bollen, K. A., \& Long, J. S. (Eds). Testing structural equation models (pp. 136-162). New bury Park, CA: Sage

[83] Hu, L. T., \& Bentler, P. M. (1999). Cutoff criteria for fit indexes in covariance structure analysis: Conventional criteria versus new alternatives. Structural Equation Modeling: A multidisciplinary journal, 6(1), 1-55.

[84] Hayes, A. F. (2012). PROCESS: A versatile computational tool for observed variable mediation, moderation, and conditional process modeling 1 .

[85] Rauschnabel, P. A., He, J., \& Ro, Y. K. (2018). Antecedents to the adoption of augmented reality smart glasses: A closer look at privacy risks. Journal of Business Research, 92, 374-384.

[86] Kaur, P., Dhir, A., Rajala, R., \& Dwivedi, Y. (2018). Why people use online social media brand communities: A consumption value theory perspective. Online Information Review.

[87] Kaur, P., Dhir, A., Talwar, S., \& Ghuman, K. (2021). The value proposition of food delivery apps from the perspective of theory of consumption value. International Journal of Contemporary Hospitality Management. 
[88] Sahu, A. K., Padhy, R. K., \& Dhir, A. (2020). Envisioning the future of behavioral decisionmaking: A systematic literature review of behavioral reasoning theory. Australasian Marketing Journal (AMJ), 28(4), 145-159.

[89] Dhir, A., Koshta, N., Goyal, R. K., Sakashita, M., \& Almotairi, M. (2021). Behavioral reasoning theory (BRT) perspectives on E-waste recycling and management. Journal of Cleaner Production, 280, 124269.

[90] Laato, S., Islam, A. N., Farooq, A., \& Dhir, A. (2020). Unusual purchasing behavior during the early stages of the COVID-19 pandemic: The stimulus-organism-response approach. Journal of Retailing and Consumer Services, 57, 102224.

[91] Kumar, S., Murphy, M., Talwar, S., Kaur, P., \& Dhir, A. (2021). What drives brand love and purchase intentions toward the local food distribution system? A study of social media-based REKO (fair consumption) groups. Journal of Retailing and Consumer Services, 60, 102444. 